\title{
Gambaran Workplace Ostracism Sebagai Dampak Pengungkapan Kasus Sexual Harassment di Tempat Kerja
}

\author{
Maria Nathania Pradita Wibowo* \\ Departemen Psikologi Industri dan Organisasi, Fakultas Psikologi Universitas Airlangga
}

\begin{abstract}
ABSTRAK
Banyak korban yang menemukan keberanian untuk mengungkapkan pengalamannya tentang pelecehan seksual, namun ada juga ketakutan yang mempengaruhi keputusan untuk mengungkapkan pengalaman pelecehan seksual yang terjadi di tempat kerja kepada seseorang yang memiliki kewenangan untuk mendapatkan keadilan, salah satunya adalah workplace ostracism. Para korban yang mengalami dan mengungkap pengalaman pelecehan seksualnya di tempat kerja membantu mengungkap topik ini dengan sesi wawancara dengan peneliti. Hasil mengungkapkan bahwa pengucilan di tempat kerja memang terjadi pada mereka yang mengungkapkan pengalaman pelecehan seksual di tempat kerja baik disengaja maupun tidak disengaja. Dampak yang mereka tanggung sebagian besar bersifat psikologis dan mempengaruhi aspek perilaku atau sikap. Intervensi dan regulasi diperlukan untuk membantu para korban mendapatkan keadilan dan penyembuhan yang layak mereka dapatkan dan untuk menciptakan tempat yang aman bagi mereka untuk bekerja dan mengungkap pelecehan seksual.
\end{abstract}

Kata kunci: pengungkapan pelecehan seksual, workplace ostracism

\begin{abstract}
There's a lot of survivors who already found their courage to disclose their experience of sexual harassment, but, there's also fear that follow the decision whether or not to disclose their experience of sexual harassment that happen at workplace to someone who has authority to get justice, one of them is workplace ostracism. Survivors who experienced and disclosed their sexual harassment experience at workplace help uncover this topic with interview session with the researcher. It reveals that workplace ostracism is indeed happen to those who disclosing their experience of sexual harassment at workplace whether it's intentional or unintentional. The impact they endure mostly is psychological and it affects the behavioral or attitude aspect. Intervention and regulation is needed to help survivors get justice and healing they deserve and to create safe place for them to work and disclose sexual harassment.
\end{abstract}

Keywords: disclose sexual harassment, workplace ostracism

Buletin Penelitian Psikologi dan Kesehatan Mental (BRPKM), 2021, Vol. 1(1), 37-51

*Alamat korespondensi: Fakultas Psikologi Universitas Airlangga, Kampus B Universitas Airlangga Jalan Airlangga 4-6 Surabaya 60286. Surel: maria.nathania.pradita-2016@psikologi.unair.ac.id 
sehingga penggunaan, distribusi, reproduksi dalam media apapun atas artikel ini tidak dibatasi, selama sumber aslinya disitir dengan baik.

\section{PEN D A H U L U A N}

Kekerasan terhadap perempuan termasuk pelecehan seksual saat ini mulai mendapatkan perhatian lebih dari masyarakat, termasuk di Indonesia. Dengan munculnya berbagai gerakan dan kampanye baik online maupun offline yang mendukung kesetaraan gender dan menuntut penghapusan tindak kekerasan pada perempuan seperti \#MeToo, \#WhyIDidntReport dan Womens March, saat ini beberapa korban mulai berani bersuara baik dengan melaporkan kasus ke atasan, pihak berwenang melalui lembaga-lembaga kemasyarakatan atau menyuarakan pengalamannya kepada orang terdekat atau melalui sosial media. Menurut Catatan Tahunan Komnas Perempuan 2020, jumlah kasus kekerasan terhadap perempuan yang dilaporkan ke Komnas Perempuan pada tahun 2019 meningkat sebesar $6 \%$ sebesar 431.471, dari jumlah tahun sebelumnya yaitu sebesar 406.178 (Komnas Perempuan, 2020).

Kita tidak bisa menutup mata akan kemungkinan resiko dan dampak negatif yang diterima korban. Ketakutan banyak korban jika melaporkan kasus pelecehan adalah mendapati resiko dan dampak negatif berupa pembalasan dendam (retaliation) atau diasingkan (ostracism). Hasil survey yang dilakukan oleh kelompok inisiatif Never Okay bersama Indonesia Business Coalition for Women Empowerment (IBCWE) di tahun 2019 menunjukkan bahwa sebanyak 29\% responden memilih tidak melaporkan kasus pelecehan seksual ke HRD atau manajemen karena khawatir ada pembalasan (Never Okay Project, 2019). Ketakutan tersebut menjadi masuk akal karena pada beberapa penelitian mengungkapkan bahwa kemungkinan terjadinya pembalasan dendam (retaliation) dan atau diasingkan (ostracism) sebagai dampak atas pelaporan kejadian pelecehan seksual terutama di tempat kerja oleh korban adalah benar.

Menurut Bell, dkk (2014) dan Benson \& Thomson (1982), keputusan seseorang untuk melaporkan kejadian pelecehan seksual dipengaruhi oleh ketakutan atas kemungkinan pembalasan dendam (retaliation), tidak ada yang percaya bahwa korban mengalami pelecehan, tidak ada yang dilakukan setelah melapor, dan ketakutan akan menghilangkan privasi (Foster \& Fullagar, 2018). Sedangkan menurut Clair, dkk (2019) dan Dougherty \& Hode (2016), melaporkan kasus pelecehan seksual akan menimbulkan kemungkinan terjadinya pengasingan (ostracism) dan atau pembalasan dendam (retaliation) oleh rekan kerja; dan dapat berdampak pada karir korban (Ford \& Ivancic, 2020). Ketakutan tersebut mungkin bisa tercermin dari kejadian yang menimpa Anita Hill tahun1991 dan Marion Brown di tahun 2018 (Akin, 2018; Brown \& Battle, 2019; McLeod, 2018) seperti yang sudah di jelaskan di sub bab sebelumnya. Kedua wanita ini sama-sama menghadapi ostracism dan dampak negatif lain setelah mengungkapkan pelecehan seksual yang diterima dari mantan bosnya, dimana kedua bos dari Anita Hill dan Marion Brown tersebut datang dari kalangan atas yang memiliki power serta reputasi tinggi terutama di bidang politik yang cukup mempengaruhi penerimaan treatment kedua korban terutama setelah berita pelecehan seksual yang mereka alami di ketahui publik. Ada yang memberi dukungan bagi Hill dan Brown, namun juga banyak orang yang lebih mempercayai kedua pelaku dan menganggap kedua korban hanya ingin menjatuhkan kedua politisi ber profil tinggi ini. 
Menurut Ferris, dkk (2008), ostracism di tempat kerja terjadi ketika seorang individu atau kelompok (mis. bawahan, rekan kerja atau supervisor) menghilangkan tindakan yang melibatkan anggota organisasi yang lain ketika secara sosial pantas dilakukan. Ini termasuk perilaku seperti tidak bisa berkomunikasi atau tidak ada salam yang dijawab di tempat kerja (Brown \& Battle, 2019). Ostracism di tempat kerja yang mungkin diderita seseorang sebagai akibat dari pelecehan, atau pengungkapan pelecehan, secara khusus menyebar karena penerimaan sosialnya. Pelaporan tidak terjadi dalam ruang hampa dan bahwa sementara pengungkapan memungkinkan target untuk mendapatkan dukungan yang sangat dibutuhkan dari teman, rekan kerja atau organisasi itu sendiri, itu juga mengekspos target untuk konsekuensi negatif tambahan (Bergman dkk., 2020). Jika hal tersebut terjadi, ostracism dapat berdampak pada korban. Ketika dihadapkan dengan situasi pengasingan atau bahkan isolasi, individu dapat kehilangan keterikatan pribasi (loss of personal attachment) dan ini dapat berakibat pada turunnya rasa memiliki dan penerimaan dalam kelompok (Brown \& Battle, 2019).

Menurut Neff (2011), ostracism dapat menurunkan perasaan harga diri, yang sangat berbahaya karena mempertahankan harga diri yang cukup tinggi sangat penting untuk kesejahteraan dan sebenarnya menurut Smith \& Williams (2004), ostracism memberi tahu individu bahwa mereka telah melakukan sesuatu yang tidak menyenangkan kelompok: mungkin, mereka berpikir, ada sesuatu yang salah secara pribadi dan ini mendorong terjadinya ostracism. Bahkan target ostracism yang sadar akan kemungkinan bahwa, mereka tidak bertanggung jawab atas ostracism yang terjadi pada mereka akan mengalami penurunan harga diri. Ostracism di tempat kerja menurut O’Reily \& Robinson (2009) dapat mengurangi interaksi sosial antarpribadi, membuatnya lebih sulit untuk memenuhi kebutuhan psikologis (Brown \& Battle, 2019). Ostracism sendiri dapat menyebabkan meningkatkan angka turnover atau niat untuk meninggalkan tempat kerja (Ferris dkk., 2008).

Melihat rumitnya situasi ini dan penelitian yang masih minim untuk mengungkap seluk beluk pengalaman workplace ostracism yang diterima korban sebagai dampak dari pengungkapan kasus sexual harassment yang dialami di tempat kerja serta menganggap bahwa perlakuan ostracism ini merupakan tindakan yang secara sosial masih bisa diterima dan tidak berbahaya baik secara fisik maupun psikologis, serta kemungkinan untuk perusahaan melarang tindakan ini sangatlah kecil, padahal sebenarnya menurut Robinson, dkk (2013) tindakan dan perlakuan pengasingan atau ostracism ini sangat berbahaya (Brown \& Battle, 2019) dan ini embawa peneliti pada keinginan untuk jauh lebih dalam mengeksplor dan mengungkap pengalaman ostracism yang dialami korban. Seperti yang dikatakan Cortina \& Magley (2003); Hu (2017), dan Porter (2018) tindak pembalasan atau retaliation merupakan perhatian utama bagi banyak korban pelecehan seksual, yang menghindari melaporkan pelecehan mereka untuk menghindari perilaku ini. Banyak literatur tentang ketakutan akan pembalasan atau retaliation terhadap korban pelecehan seksual hanya merujuk pada hasil nyata yang terkait dengan pekerjaan seperti pemutusan hubungan kerja atau peluang ditolak untuk pelatihan dan promosi kenaikan jabatan. Namun, masih sangat sedikit penelitian tentang pelecehan dan pembalasan seksual yang berfokus pada pengasingan (ostracism) sebagai akibatnya (Brown \& Battle, 2019). Maka dari itu peneliti ingin meneliti dan mengetahui secara mendalam gambaran workplace ostracism, termasuk bentuk dan dampak yang diterima korban sebagai dampak pengungkapan kasus sexual harassment di tempat kerja. 


\section{Desain Penelitian}

\section{E T O D E}

Penelitian ini menggunakan metode kualitatif dimana menurut Ritchie \& Lewis, (2003), penelitian kualitatif mempunyai tujuan yang diarahkan untuk memberikan pemahaman mendalam dan penafsiran dari dunia sosial subjek penelitian dengan mempelajari tentang keadaan sosial dan material, pengalaman, perspektif, dan sejarah yang dimiliki subjek penelitian. Penelitian kualitatif akan menghasilkan data yang sifatnya deskriptif, seperti transkrip wawancara, catatan lapangan, foto, peta, dokumen, dan lainnya (Poerwandari, 2007). Penggunaan pendekatan penelitian ini dirasa lebih efektif jika dilakukan dengan pendekatan kualitatif karena melihat tema penelitian yang diangkat, penelitian kualitatif dapat mengungkapkan kompleksitas realitas sosial yang diteliti dengan sebuah narasi, sehingga memungkinkan pembaca untuk lebih memahami kedalaman, makna, dan interpretasi keutuhan suatu fenomena yang diteliti (Poerwandari, 2007).

Peneliti menggunakan metode pendekatan studi kasus, dimana peneliti mengeksplor suatu kasus baik tunggal maupun ganda (beberapa kasus) dalam jangka waktu tertentu melalui pengumpulan data yang detail dan mendalam dengan menggunakan beberapa sumber data seperti wawancara, observasi, dokumen pendukung, dan lainnya (Stake, 1995). Kasus yang menarik perhatian peneliti yang nantinya akan digambarkan lebih terperinci adalah workplace ostracism sebagai dampak penyingkapan kasus pelecehan seksual yang diterima korban di tempat kerja, yang mana nantinya akan digambarkan lebih terperinci mengenai bentuk workplace ostracism dan dampak yang diterima. Dengan studi kasus, peneliti dapat mengungkapkan bagaimana dan mengapa suatu kasus dapat terjadi dalam penelitiannya (Yin, 2016). Secara spesifik, studi kasus yang digunakan dalam penelitian ini menggunakan penelitian studi kasus instrumental.

\section{Partisipan Penelitian}

Dalam pemilihan partisipan penelitian yang diperlukan, peneliti akan menggunakan teknik purposive sampling atau pengambilan sampel perposif yang terstratifikasi. Peneliti berupaya menangkap variasivariasi besar dari objek penelitian dan dengan teknik ini, sampel tidak diambil secara acak, tetapi dipilih mengikuti kriteria tertentu (Poerwandari, 2007). Kriteria partisipan yang sesuai dengan topik dan tujuan penelitian, diantaranya (a) sedang atau pernah bekerja, (b) pernah mengalami pelecehan seksual di tempat kerja dan melaporkannya ke pihak berwajib atau pihak yang memiliki kewenangan (seperti: atasan, pihak management, polisi, atau pihak berwenang lainnya), (c) menjadi target workplace ostracism. Korban pelecehan seksual di tempat kerja yang pernah melaporkan pengalamannya dan target workplace ostracism dalam penelitian ini diketahui melalui screening dengan kuesioner berisikan pertanyaan mengenai pelecehan seksual yang diterima ditempat kerja beserta pengungkapan pelecehan seksual yang dialami berdasarkan teori Fitzgerald, dkk (1995) dan pertanyaan mengenai pengalaman workplace ostracism berdasarkan teori Ferris, dkk (2008).

Setelah mendapat beberapa calon partisipan dari beberapa informan dan kenalan, terkumpul sebanyak 12 orang yang dapat masuk proses screening dan dari 12 orang, hanya 5 orang yang memenuhi kriteria yang sudah di tentukan. Dari 5 partisipan, hanya 3 orang yang dapat dihubungi dan menyetujui untuk di wawancara. 1 orang tidak dapat dihubungi hingga proses pengambilan data berakhir dan 1 orang lainnya tidak bersedia untuk dilakukan wawancara. Partisipan yang berpartisipasi dalam penelitian ini ketiganya berjenis kelamin perempuan dengan rentang usia antara 20-28 tahun. Ketiganya sudah bekerja dengan profesi yang berbeda, seperti terapis, pelayan coffee shop, dan pegawai magang di sebuah universitas. 


\section{Strategi Pengumpulan Data}

Peneliti menggunakan tipe wawancara dengan pedoman umum. Dengan tipe wawancara ini, peneliti akan mewawancara dengan pedoman yang sangat umum yang hanya mencantumkan isu-isu yang harus diliput, tanpa menentukan urutan pertanyaan dan bentuk pertanyaan yang eksplisit (Poerwandari, 2007) serta karena peneliti ingin melakukan wawancara secara mendalam namun tidak kaku dan tetap terarah, maka tipe ini dirasa tepat guna mendapatkan data secara menyeluruh. Pedoman wawancara yang digunakan disusun berdasarkan teori workplace ostracism dari Robinson, O’Reily, dan Wang (2013). Setelah mendapatkan data dari wawancara, kredibilitasnya di pastikan kembali oleh peneliti menggunakan metode pemantapan kredibilitas atau validasi data menurut Sarantakos (1993) yaitu validitas komunikatif. Setelah melakukan wawancara dan menyusun data ke dalam bentuk transkrip, peneliti memastikan kembali data yang didapat, apakah sudah tepat atau ada yang perlu di tambah dan di konfirmasi kembali (Poerwandari, 2007). Hal ini dilakukan karena penelitian ini berfokus pada pengalaman dari partisipan sebagai korban pelecehan seksual yang mengalami workplace ostracism karena melaporkan pengalamannya untuk melihat sebenarnya ostracism yang dialami partisipan seperti apa dan perasaan serta keadaan partisipan seperti apa, karena yang mengalami kejadian dan yang merasakan dampaknya atas perlakuan tersebut adalah partisipan sendiri, maka peneliti merasa metode ini lebih tepat untuk digunakan.

\section{Analisis Data}

Setelah peneliti mengumpulkan data-data yang mendukung penelitian, peneliti akan melakukan pengorganisasian data yang telah didapat dengan melakukan coding untuk mengorganisir dan mensistemasi data-data secara lengkap dan detail sehingga dapat memunculkan gambaran tentang topik yang dipelajari (Poerwandari, 2007). Analisis data yang digunakan dalam penelitian ini adalah analisis dengan pendekatan tematik dengan pendekatan theory driven, dimana tema-tema ditemukan melalui prosedur analisis dengan pengkodean yang berbasis pada teori. Peneliti menganalisis data mengacu pada teori bentuk dan dampak workplace ostracism dari Robinson, O'Reily, dan Wang (2013). Dengan penggunaan pendekatan ini, memungkinkan peneliti untuk menemukan pola yang bisa saja pihak lain tidak dapat melihatnya dengan jelas (Poerwandari, 2007). Data yang sudah melewati proses pengkodean dapat menghasilkan daftar tema, model tema, atau indikator yang kompleks.

\section{H A S I L P E N E L I T I A N}

Ketiga partisipan mengalami bentuk pelecehan yang berbeda, dimana partisipan 1 mengalami pelecehan fisik, verbal, hingga gesture dari klien laki-laki yang ia layani. Ini terjadi ketika partisipan sedang melakukan perawatan bagi klien tersebut. Pada partisipan 2, partisipan mengalami pelecehan verbal oleh seorang supervisor dan barista yang bekerja dengan partisipan, dimana anggota tubuhnya di komentari tepatnya bagian payudara dan dijadikan bahan bercandaan yang cukup menyinggung partisipan. Pada partisipan 3, partisipan mengalami bentuk pelecehan verbal dan emotional, dimana partisipan mendapatkan komentar-komentar kurang pantas mengenai proporsi tubuhnya, dibandingkan dengan pemeran film dewasa, mendapat berbagai komentar seksis serta menerima percakapan berbau seksual, dan terus diajak kencan, keluar makan siang oleh rekan kerja laki-laki yang bekerja di satu bagian yang sama, dimana ajakan ini sangat tidak dikehendaki dan membuat partisipan tidak nyaman. 
Ketiga partisipan akhirnya melaporkan kejadian yang dialami ini kepada pihak yang memiliki kewenangan di tempat kerjanya dan respon yang diterima ketiga partisipan juga berbeda-beda. Pada partisipan 1, partisipan melaporkan kejadian pelecehan ini kepada head staff nya dan keluhan permasalahan partisipan ini didengarkan oleh head staff dan sangat mendukung partisipan yang juga sesama perempuan. Bahkan sang head staff ini juga membantu dan sangat memperhatikan partisipan agar dapat mengatasi traumanya sehingga partisipan bisa kembali bekerja seperti semula. Berbeda dari partisipan 1, partisipan 2 malah mendapat respon yang kurang baik. Partisipan mengungkapkan kejadian ini kepada leader nya. Namun, masalah partisipan ini hanya ditanggapi bukan dengan dukungan tetapi dengan menyalahkan cara berpakaian partisipan yang dianggap terlalu memperlihatkan bentuk tubuhnya terutama bagian payudara dan diminta untuk berpakaian yang lebih pantas lagi. Setelah kejadian ini, tidak ada perubahan dalam tempat ia bekerja, semuanya tetap kembali bekerja seakan tidak ada yang terjadi, serta tidak terjadi apa-apa atau perubahan terkait masalah pelecehan pada pelaku pelecehan. Partisipan 3 juga mendapat respon yang negatif. Setelah mengungkapkannya, mentor memberikan respon dimana ia tidak percaya atas apa yang terjadi pada partisipan dan menganggap bahwa itu hanya imajinasi partisipan belaka. Mentor lebih mempercayai pelaku, melihat sikap dan perilaku kerja pelaku di tempat kerja dan pengalaman selama mengenal pelaku. Mendengar tanggapan itu, partisipan sangat kecewa dan setelah melaporkan itu tidak ada tindakan apa-apa yang diambil, laporan tersebut hanya berhenti sampai pada mentornya, dan malah menyebar ke rekan kerja yang lain.

Karena hal itu, ketiganya mendapatkan perlakuan ostracism yang mana bentuknya berbeda-beda serta pelakunya juga berbeda. Pada partisipan 1, melihat partisipan sangat di perhatikan oleh atasannya itu, ada beberapa rekan kerja ( 2 orang) yang terganggu dengan apa yang terjadi. Rekan kerja tersebut menjadi sinis serta menjauhi partisipan dan tidak menghiraukan keberadaan partisipan. Karena perlakuan ini, suasana di tempat kerja partisipan menjadi berubah dan menghambat pekerjaan partisipan karena, jika partisipan bertanya terkait letak barang atau mengenai inventory kepada 2 rekan kerja tersebut, selalu tidak di jawab dan malah menjadi di marahi dan di omeli. Pada partisipan 2, partisipan merasa kurang nyaman dan canggung terutama jika berinteraksi dengan pelaku pelecehan, karena tindakan yang mereka lakukan. partisipan merasa pelaku pelecehan juga menjauhi dirinya. Karena ini terdapat jarak antara partisipan dengan pelaku pelecehan untuk beberapa saat. Walaupun begitu, partisipan berusaha untuk bisa melintasi jarak tersebut, apalagi jika urusannya dengan pekerjaan agar alur komunikasi kerja tetap berjalan dan pekerjaan serta dinamika kerja coffee shop tidak terhambat.

Berbeda lagi dengan partisipan 3. Partisipan 3 setelah melapor, partisipan merasa sang mentor menjauhi dirinya. Setelah kejadian itu, rekan kerja partisipan yang lain jadi mendengar kabar tersebut dan mulai muncul rumor mengenai dirinya dan pelaku pelecehan yang menurut partisipan sangat tidak benar. Karena itu, rekan kerjanya termasuk mentornya menghindari dirinya, memandangnya aneh serta menjadi di remehkan oleh rekan kerjanya. Menurutnya, pelaku pelecehan memiliki andil dalam penyebaran rumor tersebut, karena pelaku pelecehan juga sering membicarakan partisipan. Partisipan mengatakan karena pelaku pelecehan memiliki citra yang begitu sempurna di tempat kerja, dimana ia sangat baik, sering membantu rekan-rekan kerjanya, orang-orang di tempat kerja partisipan jadi memiliki respect pada pelaku dan cukup disegani, sehingga orang-orang di tempat kerja apalagi sang mentor yang sudah cukup mengenal pelaku pelecehan cenderung lebih mendengarkan pelaku bahkan 
tidak meminta konfirmasi pada partisipan, maka partisipan menjadi semakin pandang aneh.

Akibat kejadian tersebut, terdapat beberapa dampak yang dirasakan partisipan. Pada partisipan 1, setelah mendapat bantuan, dibimbing, dan diperhatikan lebih oleh atasan sebagai usaha untuk membantunya kembali bekerja seperti semula, beberapa rekan kerjanya jadi menjauhi dan membicarakannya. Partisipan merasakan dampak secara pragmatis yang langsung dirasakan, dimana dengan dijauhi, suasana kerja menjadi berubah serta komunikasi terutama dengan rekan kerja yang menjauhinya menjadi terhambat sehingga pekerjaannya jadi terhambat pula. Kejadian tersebut juga mempengaruhi psikologis partisipan dimana ia menjadi merasa tersingkir dan merasa seperti penjahat. Partisipan juga merasa jengkel kecil hati jika rekan kerjanya yang menjauhinya bersikap tidak acuh terutama jika menyangkut pekerjaan. dan ini juga membuat partisipan meragukan dirinya serta segala keputusan yang pernah ia buat hingga semua itu terjadi. Hal tersebut berakibat pada perubahan perilaku dalam bekerja. Di satu sisi, walaupun ia merasakan seluruh dampak tersebut, pandangannya akan kemampuan dirinya tidak berubah yang mana hal itulah yang membuatnya masih bisa bertahan ketika bekerja, sehingga ia berusaha untuk bisa bekerja maksimal dan tidak terlalu menghiraukan perlakuan rekan-rekan kerjanya. di sisi lain, perlakuan-perlakuan tersebut mempengaruhi perilaku partisipan dimana ia menjadi tidak fokus, sering merasa takut, kruang berperan, hanya bekerja sesuai dengan apa yang ditugaskan, serta menjadi lebih diam dan pasif di lingkungan kerja.

Pada partisipan 2, kejadian tersebut cukup mempengaruhinya secara psikologis, dimana mood atau perasaannya menjadi turun dan berubah serta pandangan dirinya berubah dan meragukan diri sendiri, sehingga itu mengakibatkan pada perilakunya di tempat kerja, dimana ia menjadi lebih lambat dalam bekerja, kecepatannya turun, dan menjadi lebih diam dan pasif di lingkungan kerjanya. namun, hal tersebut ternyata tidak mempengaruhi sense of control nya karena ia masih memiliki otonomi pribadi atas dirinya serta sense of self dimana ia masih merasa mampu dan meyakini kemampuannya dalam bekerja. Partisipan juga membentuk perilaku positif dimana, partisipan masih berusaha untuk mendobrak dan berusaha untuk bersosialisasi, berkomunikasi dengan rekan-rekan kerjanya dan bekerja dengan maksimal.

Pada partisipan 3, perlakuan yang diterima berdampak secara psikologis, dimana partisipan merasa sedih, resah, juga kesal. Partisipan menjadi merasa worthless, tidak menyukai diri sendiri, dan tidak merasa penting di antara lingkungan kerjanya. partisipan juga menjadi tidak percaya diri dan sense of control menjadi rendah. Karena itu, perilaku partisipan juga ikut terdampak dimana partisipan menjadi menarik diri dari rekan kerjanya dan menjadi kurang berperan dalam tempat kerja (less in role behavior), serta menjadi lebih diam dan pasif jika ada rapat atau kegiatan di tempat kerja. namun, perilaku positif juga terbentuk, dimana walaupun ia mendapat perlakuan tersebut, partisipan masih berusaha untuk bekerja maksimal dan membangkitkan pikiran positif agar pekerjaannya tidak semakin terganggu.

\section{I S K U S I}

Dari penjabaran diatas, dapat diketahui gambaran workplace ostracism sebagai dampak dari pengungkapan kasus pelecehan seksual di tempat kerja. Diketahui bahwa ternyata ketika individu terutama korban memutuskan untuk mengungkapkan kasus pelecehan yang dialami, secara khusus dalam penelitian ini adalah pelecehan yang dialami di tempat kerja, terdapat akibat dan dampak yang 
akan mengikuti. Workplace ostracism menjadi salah satunya, dimana ini mengkonfirmasi hasil penelitian yang dilakukan oleh Clair, dkk (2019); Dougherty \& Hode (2016); dan Pierce, dkk (1997). Tetapi bukan hanya workplace ostracism yang dapat diterima korban sebagai akibat dari membuka suara, tetapi juga victim blaming, dimana menurut Adams, dkk (1983); Fitzgerald, dkk (1988); dan Jensen \& Gutek (1982), takut disalahkan oleh pelaku atau orang lain dan menyalahkan diri sendiri adalah salah satu penghalang yang signifikan bagi korban untuk melaporkan pelecehan seksual (Judibicus \& McCabe, 2001).

Korban yang berani bersuara harus mengemban beban dua kali lebih berat karena setelah mendapat pelecehan, mereka menjadi dijauhi, dihindari, tidak diacuhkan di lingkungan kerja. Bentuk-bentuk workplace ostracism yang diterima pun berbeda-beda, tergantung pada persepsi, pemahaman baik pelaku, bystander, dan korban sendiri, serta alasan dibalik pemberian ostracism karena menurut Zhao, dkk (2016), persepsi seseorang tentang apakah dirinya diasingkan atau tidak adalah subjektif. Ini juga tergantung pada pemahaman dan persepsi akan sexual harassment itu sendiri, karena apabila bystander dan pelaku hanya menganggap pelecehan sebagai bercandaan atau sesuatu yang tidak mungkin, maka korban hanya akan dipandang sebagai orang "aneh" dan tidak dianggap serius karena tidak semua orang dalam konteks sosial tertentu akan menyetujui apa yang dianggap sebagai perilaku yang pantas secara sosial. Ketika anggota kelompok, departemen, atau seluruh organisasi berbagi pemahaman yang berbeda mengenai perilaku seperti apa yang sesuai secara sosial karena ini berkaitan dengan keterlibatan sosial, disini ostracism yang tidak disengaja dapat terjadi sesuai dengan norma atau moral bersama (Robinson dkk., 2013).

Ada tidaknya dukungan sosial di tempat kerja, power, status, budaya dan lingkungan kerja, serta leadership dalam suatu organisasi atau tempat kerja juga menentukan kemungkinan terbentuk atau tidaknya perlakuan ostracism di tempat kerja, yang mana ini dapat mempengaruhi tingkatan dampak yang dirasakan oleh korban. Menurut Davis \& Moore (1945) kekuasaan dan status memiliki hubungan dimana mereka yang memiliki status organisasi lebih tinggi cenderung lebih berkuasa daripada mereka yang menempati status lebih rendah. Jika seorang bawahan mengalami ostracism oleh atasan, atau rekan kerja maupun individu dengan status yang lebih tinggi akan sangat rentan terhadap perampasan sumber daya (Fiset dkk., 2017). Selain itu, seseorang yang memiliki status lebih tinggi dan berada pada posisi sentral dalam jaringan pertemanan menurut Aquino \& Lamertz (2004), memiliki akses referensi dan kekuasaan yang sah dan karena terbukanya akses tersebut individu memiliki pengaruh lebih dalam dinamika sosial misal seperti perlindungan, pemberian dukungan, bahkan pengaruh sosial (Sias, 2009). Jika seseorang tidak memiliki dukungan hubungan sosial di tempat kerja maka korban ostracism sebagai individu tidak memiliki sumber daya untuk mempengaruhi rekan-rekan kerjanya (Williams, 1997).

Menurut Halevy, dkk (2014) dan Wu, dkk. (2015), lingkungan kerja yang kompetitif telah terbukti individu mengucilkan (ostracize) orang lain demi posisi dan kemajuan individu, sedangkan lingkungan kerja yang kooperatif telah terbukti mengurangi ostracism di tempat kerja (Howard dkk., 2019), dimana ini terlihat pada partisipan 1. Selain itu, leadership dalam suatu organisasi juga bisa mempengaruhi munculnya ostracism di tempat kerja. Pemimpin dengan dengan tingkat leader-member exchange rendah dapat menyebabkan karyawannya merasa terputus satu sama lain. Ini bisa menyebabkan karyawan dapat meyakini bahwa hubungan kerja tidak dihargai dan terjadinya ostracism karena kemungkinan adanya resiko hukumannya yang kecil, terutama jika berniat mengasingkan karyawan dengan kualitas hubungan rendah dengan pemimpin (Howard dkk., 2019).

Apapun bentuk ostracism, pelakunya, dan alasan dibaliknya yang diterima korban, dampaknya samasama berat. Ostracism dapat mengakibatkan perubahan secara pragmatis dan secara psikologis yang mana akan berpengaruh pada perilaku atau attitude dalam lingkungan kerja. Menurut Robinson, dkk 
(2013), dampak yang dapat dirasakan target ostracism diantaranya adalah dampak pragmatis dan psikologis. Dampak pragmatis dan psikologis yang dialami target ini akan berdampak pula pada pembentukan perilaku atau attitude target. Pada aspek psikologis terdapat 2 aspek yang terdampak apabila individu menjadi target ostracism, yaitu: need, dan affective. Menurut Baumeister \& Leary (1995); Richman \& Leary (2009); dan Williams (1997) salah satu kebutuhan psikologis penting yang terancam ketika seseorang diasingkan (ostracize) - adalah kebutuhan need to belong (Robinson dkk., 2013). Partisipan 1 merasakan dampak ini, dimana karena merasa dijauhi dan tidak dihiraukan, ia merasa tersingkir dan merasa dirinya seperti penjahat. Kebutuhan psikologis yang terancam jika seseorang menjadi target ostracism adalah sense of self atau self-esteem, ini dapat terjadi karena self esteem asalnya muncul dari perlakuan yang didapat dari orang lain (Robinson dkk., 2013).

Workplace ostracism dapat berdampak pada affective atau perubahan emosi serta perasaan seseorang secara general. Menurut Buckley, dkk (2004) ostracism dapat memunculkan kesedihan (sadness) dan menurut Leary, dkk (1998) ostracism dapat menyebabkan sakit hati (generalized hurt), rasa marah seperti yang dikatakan Chow, dkk (2008) dan Zadro, dkk (2004), serta rasa malu (shame) seperti yang dikatakan Chow, dkk (2008) (Robinson dkk., 2013). Ketiga partisipan mengalami perubahan emosi dimana mereka merasa jengkel seperti partisipan 1; merasa sedih, resah, dan kesal seperti partisipan 3; dan merasa berat serta mood yang turun sehingga menjadi diam dan murung. Ketika dampak pragmatis dan psikologis muncul akibat workplace ostracism, maka akan berakibat pada perubahan perilaku atau attitude seseorang. Perubahan perilaku ini dapat berubah ke arah positif maupun negatif. Menurut Robinson, dkk (2013), Individu yang menjadi target ostracism akan berusaha mengambil hati orang lain, meingkatkan kepatuhannya, berusaha bekerja lebih keras untuk kelompoknya. Ketiga partisipan mengalami perubahan ini. Karena mereka sudah pasrah dengan perlakuan yang diberikan pada mereka, Ketiga partisipan akhirnya berusaha untuk tetap bekerja semaksimal mungkin dan mematuhi segala tugas atau perintah yang diberikan agar dapat membuahkan hasil kerja yang memuaskan. Partisipan 2 bahkan berusaha untuk bersosialisasi dan mengusahakan komunikasi pada rekan kerja terutama pelaku agar jalur komunikasi setidaknya saat bekerja tidak terganggu.

Perilaku negatif juga dapat terbentuk dimana terjadi penarikan perilaku (withdrawal), memunculkan perilaku pasif dan cenderung melepaskan diri (disengagement) dimana akan menyebabkan individu kurang berperan (less in-role behavior), serta dapat berdampak pada penurunan performance individu dalam organisasinya. Pada partisipan 1, partisipan mengerjakan tugas semua yang diberikan sesuai porsi dan sesuai dengan yang ditugaskan saja karena ingin menghindari pandangan dan pembicaraan tentang dirinya serta menjadi pasif saat bekerja. Pada partisipan 2, partisipan merasa mood kerja nya menjadi berubah, tidak semangat, kecepatan kerja menurun sehingga performancenya turun, serta menjadi lebih murung dan pasif saat bekerja. Pada partisipan 3, partisipan menarik diri dari rekan kerjanya, bersikap pasif, bekerja hanya sekedar bekerja yang penting hasilnya dan bekerja sesuai porsi saja tidak mengerjakan hal lain selain tugasnya, serta tidak berinteraksi sosial dan aktif dalam rapat.

Walaupun bentuk dan tingkat keparahan ostracism yang diterima partisipan berbeda-beda, namun dampak yang dirasakan belum tentu mengimbangi atau sama levelnya dengan perlakuan yang diterima. Pada partisipan 1, ostracism yang diterima partisipan memang sampai menghambat pekerjaannya dan membuat kliennya menunggu, tetapi partisipan tidak merasakan dampak yang sampai merubah dirinya secara personal seperti kepercayaan dirinya hingga bagaimana ia memaknai danmelihat hidupnya. Ini sangat berbeda dengan partisipan 3, dimana ia memang mengalami ostracism dimana ia dihindari, dijauhi, dan di pandang aneh di tempat kerja namun, ia masih mendapat tanggapan apabila berkaitan dengan pekerjaan. Tetapi dampaknya cukup besar baginya karena cukup mempengaruhi dirinya sebagai pribadi, dimana self-esteem sangat turun dan sangat terpengaruh dengan omongan orang lain 
yang mana ini membuatnya sangat tertekan secara mental dan menyebabkan pekerjaannya terganggu, walaupun tidak sampai mengacau.

Dampak-dampak ini membuat beban dan akibat yang harus ditanggung korban yang sudah terluka dan cukup rapuh untuk membuka lukanya sebagai korban pelecehan seksual semakin berat dan jika tidak dibantu atau diselesaikan, dapat memunculkan masalah baru bagi korban. Karena itulah, masih banyak dari korban yang ragu-ragu untuk membuka kotak pandoranya karena tidak dapat dipungkiri lagi bahwa ketakutan seperti takut dijauhi, takut tidak dipercaya, takut disalahkan, takut dibalas dendam itu valid dan pengalaman dilecehkan saja sudah cukup menyakitkan dan sangat membawa dampak bagi seluruh aspek kehidupan.

\section{S I M P U L A N}

Pengungkapan pelecehan seksual oleh korban diikuti beberapa dampak yang dapat mempengaruhi korban itu sendiri, seperti workplace ostracism yang diterima oleh korban yang membuka suara dan mengungkapkan pelecehan seksual yang dialami, serta victim blaming juga dialami korban pelecehan yang mengungkapkan pengalaman pelecehan seksual yang dialami. Bentuk, pelaku, serta alasan dibalik pemberian workplace ostracism yang diterima korban setelah mengungkapkan pelecehan seksual berbeda-beda, dimana bentuk yang diterima tergantung dari subjektifitas pelaku, bystander, dan korban itu sendiri, serta pelaku dan alasan pemberian ostracism akan mempengaruhi tingkatan dampak yang dirasakan.

Selain itu, bentuk workplace ostracism yang diterima korban akibat mengungkapkan pelecehan seksual yang dialami di tempat kerja, baik ostracism yang disengaja maupun tidak sengaja, bergantung pada pemahaman pribadi orang-orang yang terlibat. Jika orang-orang disekitar melihat pelecehan yang diterima atau perilaku sosial yang dimunculkan korban tidak sesuai dengan nilai atau pemahaman, bahkan kesepakatan orang-orang di lingkungan sekitar, maka ostracism bisa terjadi. Selain itu pelaku ostracism dan alasan mengapa individu menerima ostracism akan mempengaruhhi seberapa besar atau kecil dampak yang dirasakan. Dampak Workplace Ostracism yang diterima korban sebagai akibat dari pengungkapan pelecehan seksual akan berakibat pada perubahan perilaku korban. Korban yang mendapat perlakuan workplace ostracism akan merasakan dampak pragmatis, yang mana ini tidak selalu langsung dirasakan, dan dampak psikologis apapun bentuknya dan ukurannya, akan berpengaruh pada perubahan perilaku atau attitude di lingkungan kerja, yang mana dapat berarti perubahan positif maupun negatif.

Untuk penelitian selanjutnya, diharapkan dapat menggali data mengenai workplace ostracism yang dirasakan korban dari sudut pandang orang terdekat, rekan kerja, ataupun orang-orang yang mengenal dan mengetahui keadaan korban pelecehan yang mendapat workplace ostracism dan mendalami dampak lain dari pengungkapan pelecehan seksual baik di tempat kerja maupun pada setting lain selain workplace ostracism, seperti victim blaming. Selain itu, dengan penelitian ini diharapkan bisa membantu memberi intervensi bagi karyawan yang mengalami ostracism atau mistreatment lain dengan penerapan program layanan EAP (employee assistance program) di tempat bekerja dan menciptakan lingkungan kerja aman bagi seluruh karyawan agar dapat bekerja dengan tenang dan aman, serta menciptakan ruang aman bagi korban atau bystander yang mengalami berbagai mistreatment di tempat kerja termasuk, ostracism. 


\section{U CAPAN TERIMAKASIH}

Penulis mengucapkan terima kasih banyak kepada seluruh pihak yang terlibat dalam penelitian ini, terutama kepada seluruh partisipan.

\section{DEKLARASI POTENSI TERJADINYA KONFLIK KEPENTINGAN}

Maria Nathania Pradita Wibowo tidak bekerja, menjadi konsultan, memiliki saham, atau menerima dana dari perusahaan atau organisasi manapun yang mungkin akan mengambil untung dari diterbitkannya naskah ini.

\section{PUSTAKA ACUAN}

Adams, J. W., Kottke, J. L., \& Padgitt, J. S. (1983). Sexual harassment of university students. Journal of College Student Personnel, 24, 484-490.

Akin, S. (2018, Februari 15). Post \#MeToo, stalled Careers, alienation still haunt sexual harassment victims. Di akses 14 Desember 2020 dari Roll Call: https://www.rollcall.com/2018/02/15/postmetoo-stalled-careers-alienation-still-haunt-sexual-harassment-victims /

APINDO. (2012). Pencegahan dan penanganan pelecehan seksual di tempat kerja [Handbook]. https://betterwork.org/wp-content/uploads/2017/09/7-L-GUIDE-2012-PencegahanPenanganan-Pelecehan-Seksual-di-Tempat-Kerja-APINDO-LG.pdf

Aquino, K., \& Lamertz, K. (2004). A relational model of workplace victimization: Social roles and patterns of victimization in dyadic relationships. Journal of Applied Psychology, 89(6), 1023-1034.

Baumeister, R. F., \& Leary, M. R. (1995). The need to belong: Desire for interpersonal attachments as a fundamental human motivation. Psychological Bulletin, 117, 497-529.

Bell, M. E., Street, A. E., \& Stafford, J. (2014). Victims' psychosocial well-being after reporting sexual harassment in the military. Journal of Trauma \& Dissociation, 15(2), 133-152.

Benson, D. J., \& Thomson, G. E. (1982). Sexual harassment on a university campus: The confluence of authority relations, sexual interest and gender stratification. Social Problems, 29(3), 236-251.

Bergman, M. E., Langhout, R. D., Palmieri, P. A., Cortina, L. M., \& Fitzgerald, L. F. (2020). The (un)reasonableness of reporting: Antecedents and consequences of reporting sexual harassment. Journal of Applied Psychology, 87(2), 230-242.

Boyatzis, R. E. (1998). Transforming qualitative information thematic analysis and code development. Sage Publications, Inc.

Brown, S. E. V., \& Battle, J. S. (2019). Ostracizing targets of workplace sexual harassment before and after the \#MeToo movement. Equality, Diversity, and Inclusion, 39(1), 53-67. 
Buckley, K. E., Winkel, R. E., \& Leary, M. R. (2004). Reactions to acceptance and rejection: Effects of level and sequence of relational evaluation. Journal of Experimental Social Psychology, 40, 14-28.

Chan, D. K.-S., Chow, S. Y., Lam, C. B., \& Cheung, S. F. (2008). Examining the job-related, psychological, and physical outcomes of workplace sexual harassment: A meta-analytic review. Psychology of Women Quarterly, 32.

Chow, R. M., Tiedens, L. Z., \& Govan, C. L. (2008). Excluded emotions: The role of anger in antisocial responses to ostracism. Journal of Experimental Social Psychology, 44, 896-903.

Clair, R. P., Brown, N. E., Dougherty, D. S., Delemeester, H. K., Geist-Martin, P., Gorden, W. I., Sorg, T., \& Turner, P. K. (2019). \#Metoo, sexual harassment: An article, a forum, and a dream for the future. Journal of Applied Communication Research, 1-19.

Cortina, L. M., \& Magley, V. J. (2003). Raising voice, risking retaliation: Events following interpersonal mistreatment in the workplace. Journal of Occupational Health Psychology, 8(4), 247-265.

Creswell, J. W. (1998). Qualitative inquiry and research design, choosing among five traditions. Sage Publication.

Davis, K., \& Moore, W. E. (1945). Some principles of stratification. Am. Sociol. Rev., 10, 242-249.

Dharma, W. S. (2011). Pelecehan seksual pada wanita di tempat kerja.

Dougherty, D. S., \& Hode, M. G. (2016). Binary logics and the discursive interpretation of organizational policy: Making meaning of sexual harassment policy. Human Relations, 69(8), 1-27.

Ferris, L. D., Brown, D. J., Berry, J. W., \& Lien, H. (2008). The development and validation of the workplace ostracism scale. Journal of Applied Psychology, 93(6), 1348-1366.

Fiset, J., Hajj, R. A., \& Vongas, O. G. (2017). Workplace ostracism seen through the lens of power. Front. Psychol, 8(1528).

Fitzgerald, L. F., Gelfand, M. J., \& Drasgow, F. (1995). Measuring sexual harassment: Theoretical and psychometric advances. Basic and Applied Social Psychology, 17(4), 425-445.

Fitzgerald, L. F., Shullman, S. L., Bailey, N., Richards, M., Swecker, J., Gold, Y., Ormerod, M., \& Weitzman, L. (1988). The incidence and dimensions of sexual harassment in academia and the workplace. Journal of Vocational Behavior, 35, 152-175.

Ford, J. L., \& Ivancic, S. R. (2020). Surviving organizational tolerance of sexual harassment: An exploration of resilience, vulnerability, and harassment fatigue. Journal of Applied Communication Research.

Foster, P. J., \& Fullagar, C. J. (2018). Why don't we report sexual harassment? An application of the theory of planned behavior. Basic and Applied Social Psychology. 
Government of India Ministry of Women and Child Development. (2015). Handbook on sexual harassment of women at workplace [Handbook].

Halevy, N., Cohen, T. R., Chou, E. Y., Katz, J. J., \& Panter, A. T. (2014). Mental models at work: Cognitive causes and consequences of conflict in organizations. Personality and Social Psychology Bulletin, 40, 92-110.

Howard, M. C., Cogswell, J. E., \& Smith, M. B. (2019). The antecedents and outcomes of workplace ostracism: A meta-analysis. Journal of Applied Psychology.

Hu, E. (2017). Why some survivors of sexual harassment and assault wait to tell their stories. Di akses 12 Mei 2020 dari National Public Radio: www.npr.org/2017/11/15/564443807/why-somesurvivors-of-sexual-harassment-and-assault-wait-to-tell-their-stories

International Labor Organization. (2010, November 23). Frequently asked questions: Sexual harassment at the workplace. Di akses 12 Mei 2019 dari ILO.org: https://www.ilo.org/wcmsp5/groups/public/---asia/---ro-bangkok/---ilojakarta/documents/publication/wcms_149651.pdf

Jensen, I. W., \& Gutek, B. A. (1982). Attributions and assignment of responsibility in sexual harassment. Journal of Social Issues, 38, 55-74.

Judibicus, M. D., \& McCabe, M. P. (2001). Blaming the target of sexual harassment: Impact of gender role, sexist attitudes, and work role. Sex Roles, 44(7).

Komnas Perempuan. (2020). Kekerasan meningkat: Kebijakan penghapusan kekerasan seksual untuk membangun ruang aman bagi perempuan dan anak perempuan catatan kekerasan terhadap perempuan tahun 2019 [Catatan Tahunan]. Komnas Perempuan.

Leary, M. R., Springer, C., Negel, L., Ansell, E., \& Evans, K. (1998). The causes, phenomenology, and consequences of hurt feelings. Journal of Personality and Social Psychology, 74, 1225-1237.

Lorenz, K., \& O'Callaghan, E. (2020). "I realized that i couldn't act normal": A qualitative study of sexual assault survivors' experiences of workplace disclosure. Journal of Family Violence.

Maypole, D. E. (1987). Sexual harassment at work: A review of research and theory. Affilia, 2(1).

McLaughlin, H., Uggen, C., \& Blackstone, A. (2009). Sexual harassment, workplace authority, and the paradox of power. American Sociological Review.

McLeod, P. (2018, Februari 23). Marion brown accused rep. John conyers of harassing her. Here's what happened after. Di akses 14 Desember 2020 dari Buzz Feed News: https://www.buzzfeednews.com/article/paulmcleod/marion-brown-spoke-up-about-sexualharassment-in-congress

Neff, K. D. (2011). Self-compassion, self-esteem, and well-being. Social and Personality Psychology Compass, 5(1), 1-12. 
Never Okay Project. (2019). Not just another year: Melawan pelecehan seksual di dunia kerja [Annual Report]. Never Okay Project.

Never Okay Project. (2019). Potret kondisi pelecehan seksual di perusahaan [Hasil Survey]. Never Okay Project.

O’Reily, J., \& Robinson, S. L. (2009). The negative impact of ostracism on thwarted belongingness and workplace contributions. Academy of Management Proceedings, 1, 1-7.

Pershing. (2003). Why women don't report sexual harassment: A case study of an elite military institution. Gender Issue, 21, 3-30.

Pierce, E. R., Rosen, B., \& Hiller, T. B. (1997). Breaking the silence: Creating user friendly sexual harassment policies. Employee Responsibilities and Rights Journal, 10(3).

Poerwandari, E. K. (2007). Pendekatan kualitatif untuk penelitian perilaku manusia. Lembaga Pengembangan Sarana Pengukuran dan Pendidikan Psikologi Fakultas Psikologi Universitas Indonesia.

Porter, N. B. (2018). Ending harassment by starting with retaliation. Stanford Law Review, 71, 41-61.

Richman, L. S., \& Leary, M. R. (2009). Reactions to discrimination, stigmatization, ostracism, and other forms of interpersonal rejection: A multimotive model. Psychological Review, 116, 365-383.

Ritchie, J., \& Lewis, J. (2003). Qualitative research practice: A guide for social science students and researchers. Sage Publications, Inc.

Robinson, S. L., O’Reily, J., \& Wang, W. (2013). Invisible at work: An integrated model of workplace ostracism. Journal of Management, 39(1), 203-231.

Sarantakos, S. (1993). Social Research. MacMillan Education Australia Pty Ltd.

Sias, P. M. (2009). Social Ostracism, cliques, and outcast. Dalam Destructive organizational communication: Processes, consequences, and constructive ways of organizing (hlm. 146-157). Routledge.

Smith, A., \& Williams, K. D. (2004). R U There? Ostracism by Cell Phone Text Messages. Group Dynamics: Theory, Research, and Practice, 8(4), 291-301.

Sommer, K. L., Williams, K. D., Ciarocco, N. J., \& Baumeister, R. F. (2001). When silence speaks louder than words: Explorations into the intrapsychic and interpersonal consequences of social ostracism. Basic and Applied Social Psychology, 23(4), 225-243.

Stake, R. E. (1995). The art of case study research. Sage Publications, Inc.

Sundaresh, N., \& Hemalatha. (2013). Theoretical orientation to sexual harassment at work place. Journal of Business Management \& Social Sciences Research, 2(4). 
Williams, K.D. (1997). Social ostracism. Aversive Interpersonal Behaviors, 133-170.

Williams, Kipling D. (2001). Ostracism: The power of silence. The Guildford Press.

Wu, L. Z., Ferris, D. L., Kwan, H. K., Chiang, F., Snape, E., \& Liang, L. H. (2015). Breaking (or making) the silence: How goal interdependence and social skill predict being ostracized. Organizational Behavior and Human Decision Processes, 131, 51-66.

Yin, R. K. (2016). Qualitative research from start to finish (2nd Edition). The Guildford Press.

Zadro, L., Williams, K. D., \& Richardson, R. (2004). How low can you go? Ostracism by a computer is sufficient to lower self-reported levels of belonging, control, self-esteem, and meaningful existence. Journal of Experimental Social Psychology, 40, 560-567.

Zhao, H., Qingxia, He, P., Sheard, G., \& Wan, P. (2016). Workplace ostracism and knowledge hiding in service organizations. International Journal of Hospitality Management, 59, 89-94. 